\title{
Por que usar RGS - Representação Gráfica de Síntese - com alunos do Ensino Fundamental 1?
}

\author{
Why use RGS - Graphic Representation of Synthesis - \\ with elementary school students 1 ?
}

\author{
Waleska C. Sieczkowski Pacheco, Priscila Zimermann, Stephania Padovani
}

RGS - representação gráfica de síntese, educação, pensamento visual, crianças

Considerando o pensamento visual enquanto área de aprendizado, a presente pesquisa busca identificar, a partir de práticas de design, elementos sobre a temática que são utilizados no Ensino Fundamental 1, além de relatar uma dinâmica sobre Representação Gráfica de Síntese - RGS com alunos do grupo citado. O estudo, de caráter exploratório, qualitativo e indutivo, sendo guiado pela Pesquisa-Ação, é composta pela fundamentação teórica sobre o pensamento visual e RGS, identificando as lacunas existentes dentro da temática. Coletou-se dados por meio de entrevistas semiestruturadas com professoras regentes e com a técnica de observação sistemática na aplicação das RGSs com os alunos. Após o levantamento teórico a partir de autores do pensamento visual e da educação, discorreu-se sobre uma dinâmica de aplicação de RGS com crianças do Ensino Fundamental 1, apresentando-se os resultados sobre a viabilidade com este público.

RGS - graphic representation of synthesis, education, visual thinking, children

Considering visual thinking as a learning area, the present study aims to identify elements on this theme that are used in elementary school, in addition to report a school activity with Graphical Representations for Synthesis- GRS with students in the group mentioned. The study, which is of exploratory, qualitative and inductive nature, is guided by Action Research and is composed of the theoretical foundation on visual thinking and GRS, in order to identify the existing gaps within the theme. Data were collected through semi-structured interviews with leading teachers and systematic observation during the application of GRS with students. The dynamics proposed with this audience proved to be viable through basic adjustments in relation to the original model, being necessary for the activity flow to be more adequate to the students' profile and the context of elementary education.

\section{Introdução}

A discussão em torno do modo como as crianças aprendem e concebem novos conhecimentos, bem como as habilidades que se pretendem na formação delas é pauta de instituições públicas e privadas ligadas à educação e ao desenvolvimento humano em todo o mundo. O relatório da Comissão Internacional sobre educação para o século XXI (2010), por exemplo, traz recomendações do que seriam os 4 pilares para uma educação mais harmoniosa, consistente e que dá autonomia, de fato, a cada ser humano está relacionada ao aprendizado do conviver, do conhecer, do fazer e do ser. Na mesma linha de pensamento, a

Anais do $10^{\circ} \mathrm{CIDI}$ e $10^{\circ} \mathrm{CONGIC}$

Kelli C.A.S. Smythe, Rafael de Castro Andrade (orgs.) Sociedade Brasileira de Design da Informação - SBDI Curitiba | Brasil | 2021
Proceedings of the $10^{\text {th }} \mathrm{CIDI}$ and $10^{\text {th }} \mathrm{CONGIC}$

Kelli C.A.S. Smythe, Rafael de Castro Andrade (orgs.)

Sociedade Brasileira de Design da Informação - SBDI Curitiba | Brazil | 2021 
Base Nacional Comum Curricular (BNCC) chama de "aprendizagens essenciais" as competências que, durante sua trajetória escolar, as crianças devem ser oportunizadas a viver. Entendendo que "aprender a aprender, (...) se contrapõem à concepção de conhecimento desinteressado e erudito entendido como fim em si mesmo" (Brasil, 2016, p.17).

Evidenciam-se, portanto o desejo e a necessidade de se fazer da formação escolar um período de aprendizado global dedicado a aprimorar habilidades que vão além de assimilar conteúdo. Torna-se responsabilidade da escola estruturar a base para comunicação e interpretação de informações, além de estimular o estudante na construção de seu próprio aprendizado. Comprometendo-se em provocar a reflexão e a análise aprofundada de uma atitude crítica em relação ao conteúdo e à multiplicidade de meios pelos quais essas informações chegam até ele.

Diante de tal cenário, este artigo traz o relato de uma experiência proposta com crianças, em ambiente escolar, antes da pandemia Covid19, portanto realizada de modo presencial, cujo objetivo foi verificar como elas trabalham visualmente com a informação e conhecimento adquirido por meio de aulas e materiais didáticos. Para tanto foi proposta a utilização de Representações Gráficas de Síntese (RGSs), que são artefatos cognitivos produzidos coletiva e colaborativamente com o intuito de discutir e revisar o conteúdo de uma aula expositiva. Tais artefatos são indicados para uma síntese ou resumo não textual abrangendo o entendimento do conteúdo de maneira visual e em grupo. Essa forma de trabalho estimula competências tanto cognitivas como relacionais, almejadas para a formação básica, contudo, até o momento estão sendo utilizadas apenas com alunos de Graduação e Pós-Graduação em Design.

A proposta traz como contribuição a oportunidade de se instigar nas crianças competências que extrapolam assistir a aulas expositivas, dando-Ihes a responsabilidade por aprofundar e pensar de forma crítica e criativa o que aprenderam durante as aulas. Além disso, ao se trazer uma ferramenta de design para o contexto escolar, ampliam-se as possibilidades da colaboração entre as áreas de Design e Educação. Entende-se que o modo pelo qual o design articula o conhecimento corrobora com as propostas de inovação pretendidas pela educação.

\section{Pensamento visual e a RGS}

Apesar de sua aparente simplicidade, a inteligência visual é complexa e traz consigo, além da capacidade de percepção, a partir do ato de ver, a capacidade de enxergar pelos "olhos da mente" e externar, com o auxílio de ferramentas gráficas adequadas, um pensamento. (Arnheim, 1969; Dondis, 2007; Roam, 2009)

Roam (2009) afirma que para além de uma maneira de externar ideias, o pensamento visual é também um modo de esclarecimento e resolução de problemas, uma vez que imagens podem representar conceitos complexos e sintetizar conjuntos de informações de maneira rápida e intuitiva a fim de facilitar seu compartilhamento e compreensão. A partir de tal premissa, este estudo traz a RGS como ferramenta para fomentar a externalização de ideias e conhecimentos, além de sintetizar conceitos aprendidos em aula. 
W. C. S. Pacheco, P. Zimermann, \& S. Padovani | Por que usar RGS -

As RGSs são artefatos cognitivos, produzidos coletivamente e colaborativamente, com o intuito de discutir e revisar o conteúdo de uma aula expositiva (Padovani, 2012). A proposta é fundamentada por três eixos teóricos - aprendizagem significativa por produção de representações, construção colaborativa de conhecimento (CCC ou 3C) e aprendizagem ativa (active learning), conforme detalhada na figura 1 a seguir (Padovani, 2012).

Figura 1: Eixos teóricos das RGSs. Fonte: Com base em Padovani, 2012.

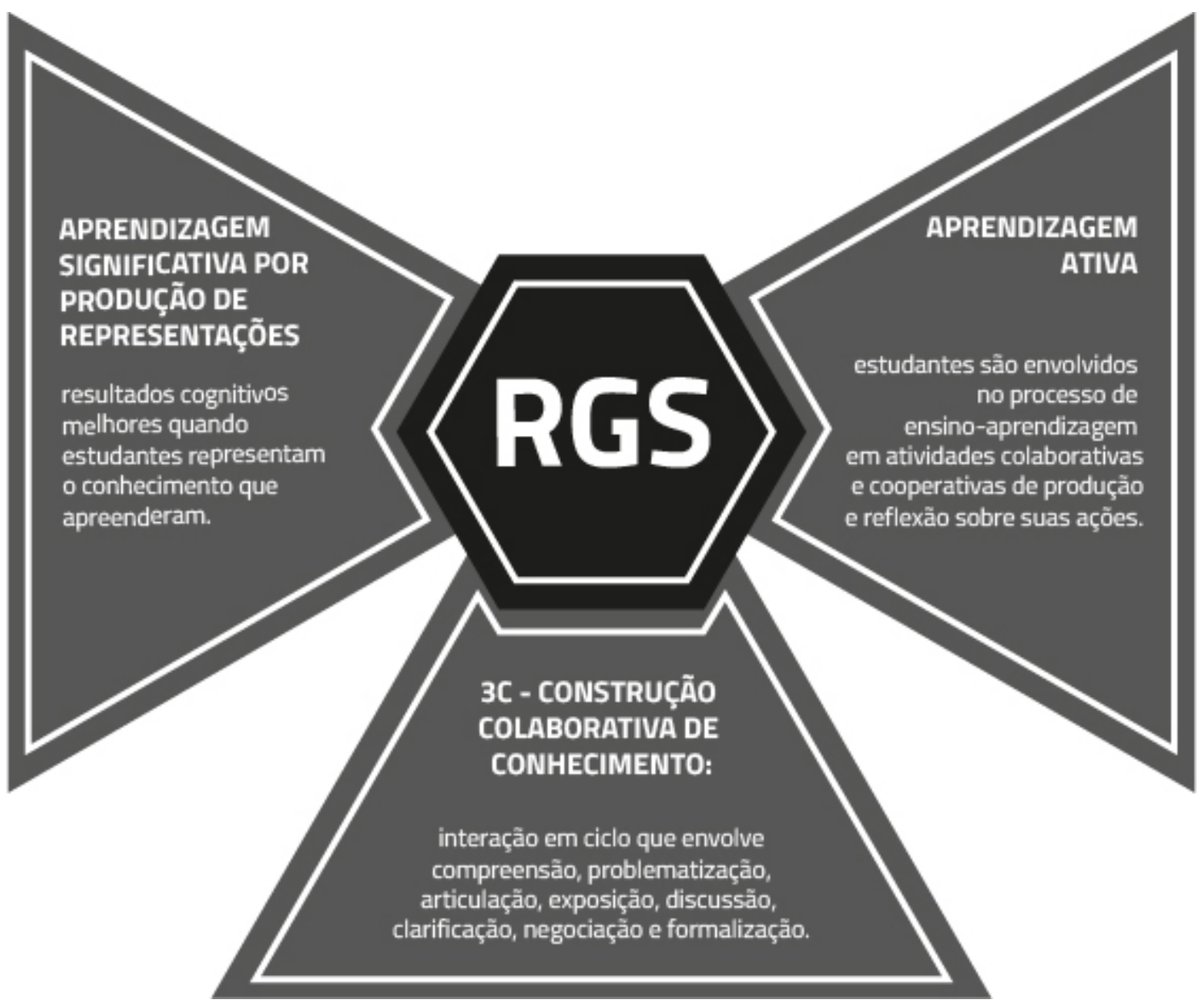

Entendendo o potencial cognitivo das RGSs, o presente estudo explorou as possibilidades da aplicação num contexto da Educação Básica, buscando identificar as oportunidades e características para o público supracitado.

\section{Por que usar RGSs no Ensino Fundamental?}

As crianças, especialmente neste século, estão expostas à informação visual muito antes da informação textual. Durante sua infância, serão continuamente apresentadas informações visuais pelos mais diversos meios e, por isso, precisam interpretá-las. (Lopatovska et al., 2016)

Em contexto escolar, os artefatos gráficos como histórias em quadrinhos e mapas conceituais, mentais e geográficos, já são utilizados com o intuito de estimular o pensamento visual por aprimorar a capacidade de visualização de ideias e conceitos bem como motivam os 
estudantes a se expressarem. "Como as representações visuais superam as barreiras linguísticas, torna-se cada vez mais importante para a economia global, os alunos aprenderem a pensar visualmente e comunicar suas ideias visualmente aos colegas e ao público em geral." (Willis; Miertschin, 2006 P. 267)

Uma vez exposta a relevância de comunicar-se visualmente e de que essa habilidade seja estimulada no início da formação do estudante, este artigo se propõe a explorar a potencialidade de aprendizado proporcionada pelo uso da RGS, não apenas como mais um artefato, mas buscando justamente o que a diferencia das demais ferramentas de pensamento visual.

De acordo com Padovani (2012), para que o estudante produza uma RGS é necessário que ele compreenda o assunto em tamanha profundidade a ponto de representá-lo de maneira gráfica ao mesmo tempo que tem a capacidade de explicá-lo para seus pares. Essa alternância entre domínio da forma e do significado amplia a fixação e compreensão dos aspectos teóricos alvos da representação. (Padovani, 2012)

São diversos os tipos de desenhos utilizados em sala de aula, cada um com suas qualidades, mas não são voltados para a estimulação da construção colaborativa do conhecimento. Os processos de desenho utilizados no contexto de sala de aula atualmente, não priorizam, e por muitas vezes não trabalham com discussão coletiva das ideias a serem construídas e representadas (Machado, 2015; Carter, 2019; Baker, 2012; Busarello E Ulbricht, 2013; Rosso; Schlögl, 2013; Barbosa et al 2004).

As representações, sejam elas mapas, histórias em quadrinhos, diagramas ou outros, ilustram as ideias de cada aluno individualmente. Percebe-se que nesses modelos de representação e a sintetização colaborativa de conteúdo não é estimulada. Na maioria das atividades em que se utiliza o desenho, esses já vêm estruturados, sejam em materiais didáticos, livros ou preparados pelo professor, com regras claras de como deverá ocorrer a construção dele. (Machado, 2015; Barbosa et al 2004)

As RGSs, por outro lado, favorecem o protagonismo do aluno enquanto ator consciente de seu processo de aprendizado e estimulando-o a construir colaborativamente referências para o conhecimento adquirido. Na figura 2, a seguir, Padovani (2012) esclarece as possibilidades de atividades a serem desenvolvidas com a RGS, assim como os benefícios cognitivos que podem ser esperados como resultado. 
W. C. S. Pacheco, P. Zimermann, \& S. Padovani | Por que usar RGS -

Figura 2: Associação atividade - benefício cognitivo previsto na produção de RGSs.

Fonte: Padovani, 2012.

\begin{tabular}{l|l}
\hline \multicolumn{1}{c|}{ atividade } & \multicolumn{1}{c}{ benefício cognitivo esperado } \\
\hline $\begin{array}{l}\text { seleção de } \\
\text { conteúdo }\end{array}$ & - revisão de conteúdo recentemente trabalhado / anterior \\
\hline sintese de & - sumarização de partes importantes do texto \\
aspectos-chave a & - foco em ideias específicas \\
representar & - identificação de informação mais abstrata e dificultosa \\
\hline seleção de & - revisão de suas dificuldades de apreensão \\
modalidades de & - aprimoramento da capacidade descritiva \\
representação & - transição entre abstrato e concreto \\
\hline integração entre & - entendimento de relações dentro do conteúdo \\
elementos & - exploração de visualização local e global do problema \\
\hline produção de & - impor estrutura ao conteúdo selecionado \\
primeira versão & - aprimoramento da capacidade descritiva \\
da RGS & - revisão de conteúdo recentemente trabalhado \\
\hline revisão da RGS & - revisão de princípios de percepção e design \\
\hline
\end{tabular}

Entendendo os benefícios das RGSs, a partir de Padovani (2012), foi proposta uma dinâmica de RGS com crianças do $4^{\circ}$ e $5^{\circ}$ anos do Ensino Fundamental 1, com intuito de entender a sua viabilidade com este público.

\section{Método}

A pesquisa realizada neste estudo caracteriza-se como qualitativa, de processo indutivo e de caráter exploratório (Sampieri; Collado; Lucio, 2013). Ela foi conduzida pelo método da Pesquisa-Ação, que conforme Santos (Santos, 2018 p. 80) envolve o desenvolvimento de artefato que ocorre ao longo dos ciclos da pesquisa de forma planejada ou incidental. O meio utilizado para a condução dos ciclos é a RGS, bem como entrevistas com professores e o relato da dinâmica com crianças do $4^{\circ}$ e $5^{\circ}$ anos de uma escola privada de Curitiba.

\section{Coleta de dados}

As técnicas utilizadas para a coleta de dados foram entrevistas semiestruturadas com professoras regentes e a técnica de observação sistemática na aplicação das RGSs com os alunos (Sampieri; Collado; Lucio, 2013). As pesquisadoras assumiram o papel tanto de participação ativa - somente observação - durante a coleta de dados, assim como a 
participação completa - momentos em que se envolviam na dinâmica esclarecendo dúvidas dos alunos e estimulando-os no processo colaborativo.

Primeiramente fez-se uma sondagem com professores antes da aplicação da RGS com os alunos, para que se pudesse entender como os professores utilizavam o desenho em suas aulas. Buscou-se compreender qual o nível de autonomia que os alunos tinham para criar sínteses visuais e como os mesmos lidavam com atividades em grupo. A entrevista com as professoras foi utilizada também para entender qual a nomenclatura utilizada com as crianças. Foram realizadas entrevistas semiestruturadas com três professoras regentes da escola participante, todas elas com participação ativa no Ensino Fundamental 1.

A aplicação da dinâmica de RGS com os alunos ocorreu com 2 turmas do Ensino Fundamental 1 da mesma escola onde atuam as professoras entrevistadas. A turma 1 ( $5^{\circ}$ ano) tinha 21 alunos e a turma 2 ( $4^{\circ}$ ano) 19 alunos. A dinâmica foi aplicada durante 2 aulas consecutivas - 100 minutos cada. Sendo que a estruturação da dinâmica foi baseada no modelo proposto por Bueno e Padovani (2015), fazendo as adaptações de tempo para o contexto do Ensino Fundamental 1 (EF1), conforme figura 3, a seguir.

Figura 3: Dinâmica de RGS. Fonte: Adaptado de Bueno; Padovani, 2015.

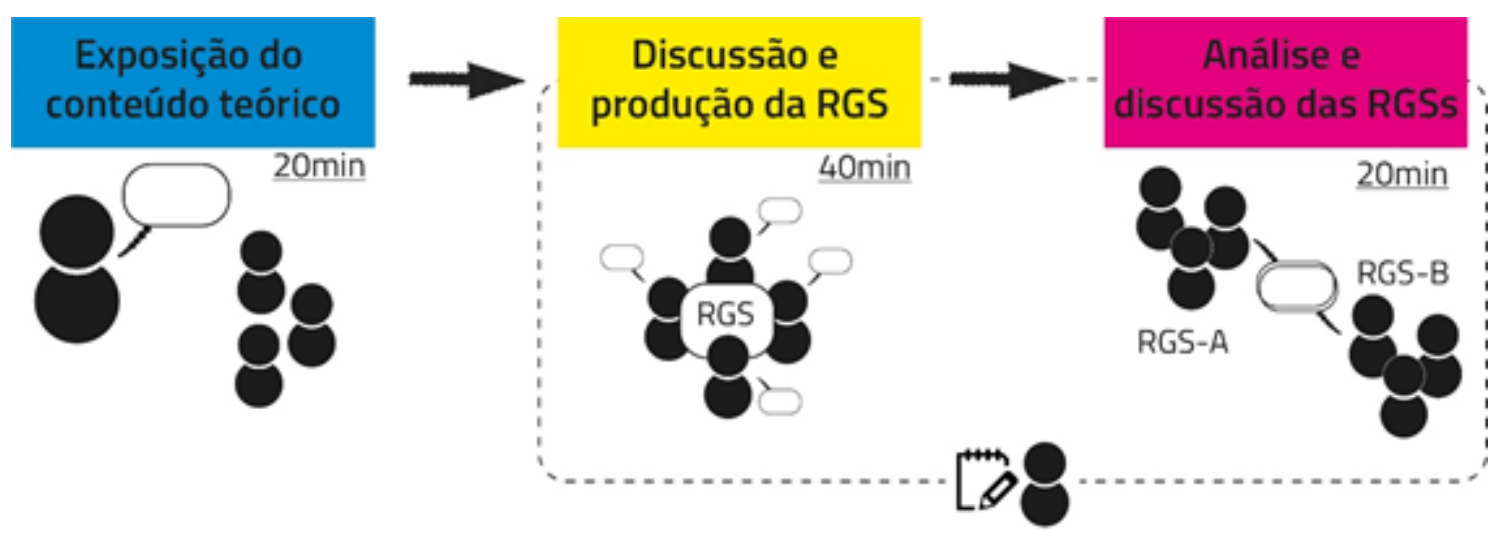

Inicialmente a professora solicitou que os alunos se dividissem em equipes (entre 3 e 5 alunos) e iniciou a exposição teórica por aproximadamente 20 minutos, utilizando o livro digital apresentado na tela interativa da sala de aula. Foram feitas as pausas necessárias para esclarecer dúvidas e questionamentos dos alunos. Sequencialmente, a professora apresentou as pesquisadoras e explicou que elas iriam conduzir uma atividade a partir daquele momento.

As pesquisadoras se apresentaram, respondendo a curiosidades dos alunos e na sequência deram a instrução sobre a produção da RGS: - "fazer um desenho colaborativo sobre o cerrado | cana de açúcar, onde todos da equipe deveriam participar de algum modo na produção dele". O tema cerrado foi trabalhado com os alunos do $5^{\circ}$ Ano e o tema cana de açúcar com os do $4^{\circ} \mathrm{Ano}$. A nomenclatura RGS não foi utilizada durante a dinâmica para que os alunos não se confundissem em relação ao que era solicitado. 


\section{Resultados}

Como resultado da entrevista com as professoras ficou claro que naquela instituição havia o uso do desenho como ferramenta em sala de aula, porém, na maioria das vezes, como é um elemento para "relaxamento" das crianças, produzido de modo individual e sem o intuito de substituir uma atividade textual ou sintetizar conteúdos aprendidos.

Os professores relataram que são diversas as técnicas utilizadas para produzir desenhos com os alunos, tais como mapas mentais e conceituais, esquemas, diagramas, histórias em quadrinhos ou mesmo desenho livre, porém não necessariamente são explicados e discutidos com os alunos as diferenças e objetivos de cada uma.

Foi possível identificar que a exploração do desenho coletivo ou colaborativo, como uma ferramenta de complemento ao conteúdo exposto em sala de aula, ainda é quase irrelevante, sendo utilizado apenas em situações em que os alunos expõem suas ideias e a professora produz a representação. Com base nas informações levantadas junto às professoras, analisouse as características das atividades de desenho utilizadas e quais as principais ações que as diferenciam das RGS, tais como formato do desenho, modo de construção, ator principal das tomadas de decisão, como se dá o processo de desenvolvimento, o tipo de material de apoio que é utilizado, a função dos atores na avaliação da produção e que tipos de estímulos podem ser trabalhados com os alunos como mostra a figura 4. 
W. C. S. Pacheco, P. Zimermann, \& S. Padovani | Por que usar RGS -

Figura 4: Visão geral dos artefatos de pensamento visual na educação básica.

Fonte: As autoras, 2021.

\begin{tabular}{|c|c|c|c|c|}
\hline & $\begin{array}{c}\text { História } \\
\text { em } \\
\text { quadrinho }\end{array}$ & $\begin{array}{c}\text { Mapa } \\
\text { conceitual }\end{array}$ & $\begin{array}{l}\text { Mapa } \\
\text { mental }\end{array}$ & RGS \\
\hline \multirow{2}{*}{$\begin{array}{c}\text { Formato do } \\
\text { desenho }\end{array}$} & $x$ & $x$ & $x$ & \\
\hline & & & & $x$ \\
\hline \multirow{2}{*}{$\begin{array}{c}\text { Modo de } \\
\text { construção }\end{array}$} & $x$ & $x$ & $x$ & \\
\hline & $x$ & $x$ & $x$ & $x$ \\
\hline \multirow{2}{*}{$\begin{array}{l}\text { Tomada de } \\
\text { decisão }\end{array}$} & $x$ & $x$ & $x$ & $x$ \\
\hline & $x$ & $x$ & $x$ & \\
\hline \multirow{3}{*}{ Processo } & & & & $x$ \\
\hline & $x$ & $x$ & $x$ & $x$ \\
\hline & $x$ & $x$ & $x$ & \\
\hline \multirow{3}{*}{$\begin{array}{l}\text { Estilo da } \\
\text { representação }\end{array}$} & $x$ & $x$ & $x$ & $x$ \\
\hline & $x$ & & & $x$ \\
\hline & & & & \\
\hline \multirow{5}{*}{$\begin{array}{l}\text { Material de } \\
\text { apoio }\end{array}$} & $x$ & & & \\
\hline & & $x$ & $x$ & $x$ \\
\hline & $x$ & $x$ & $x$ & $x$ \\
\hline & & $x$ & $x$ & $x$ \\
\hline & & & & $x$ \\
\hline \multirow{3}{*}{ Avaliação } & $x$ & $x$ & $x$ & $x$ \\
\hline & & & & $x$ \\
\hline & & & & $x$ \\
\hline \multirow{3}{*}{ Estímulos } & & & & $x$ \\
\hline & & & & $x$ \\
\hline & $x$ & & & $x$ \\
\hline
\end{tabular}

A explicação do que é a RGS foi dada ao final da entrevista, assim como as possibilidades de usos. Essa explicação tardia foi necessária para que não interferisse ou influenciasse as respostas anteriores e neste momento o intuito era entender qual o público possível para se aplicar a dinâmica. As professoras afirmaram que a síntese de informação colaborativa seria mais adequada a partir do $3^{\circ}$ Ano do Ensino Fundamental, pois atualmente, os alunos estão amadurecendo cada vez mais tarde devido às grandes proteções paternas e pouco estímulo fora de sala de aula. Com isso se determinou o público-alvo da dinâmica em sala de aula: alunos do $4^{\circ}$ e $5^{\circ}$ anos do ensino fundamental 1.

Na sequência os alunos iniciaram a produção da RGS em uma folha formato A3 (210 x 297 $\mathrm{mm}$ ), e utilizando materiais de desenhos que já possuíam, tais como canetas hidrocor, lápis de cor, cola, tesoura, fitas adesivas, além de revistas, papéis coloridos para recorte e post it fornecidos pelas pesquisadoras.

No início da atividade as crianças pediram confirmação sobre as instruções, questionando sobre o uso de outros materiais como recortes em papel. O uso do papel serviu como uma atividade a mais na divisão das tarefas, algumas crianças foram encarregadas de recortar, 
outras de desenhar, pintar ou escrever. Percebeu-se que os alunos elencaram tarefas conforme as habilidades individuais.

Observou-se que as crianças estavam dispensando muito tempo no planejamento do desenho e na discussão, então foi solicitado que escrevessem - por tópicos ou texto - o que gostariam de representar, o que acharam curioso ou novidade sobre o conteúdo exposto pela professora. Neste momento os alunos receberam uma folha A4 em branco, fato que foi complexo para alguns alunos que precisaram desenhar as linhas de apoio para a escrita. A discussão foi estimulada, porém com a ressalva de que já fossem produzindo a representação colaborativamente, ou seja, todos poderiam desenhar e escrever ao mesmo tempo.

É importante ressaltar que na turma do $4^{\circ}$ Ano a professora deixou anotado no quadro os tópicos discutidos durante a exposição, como forma de reforço do conteúdo e por já ser uma prática usual com aqueles alunos. Durante o planejamento do desenho algumas crianças buscaram por referências em seus próprios desenhos no caderno ou nos livros didáticos. Além disso, na consulta de materiais houve a busca por cores e algumas crianças questionaram sobre qual seria a mais adequada para representar os elementos que gostariam.

Durante a dinâmica os alunos se mostraram bem engajados e atentos a representar todo o conteúdo apresentado, buscando correlações com outros conteúdos já aprendidos, durante a fala e exemplificando para que todos do grupo compreendessem os diferentes pontos de vista.

As RGSs foram sendo construídas e surgiram situações como da figura 6 , a seguir, em que a equipe se preocupou em transmitir por meio do desenho as sensações físicas que desejavam: passaram diversas camadas de caneta corretiva branca sobre as nuvens para que elas ficassem "fofas" - palavra dos alunos. 
Figura 5: RGS produzida pelos alunos do $5^{\circ}$ ano. Fonte: As autoras, 2021.

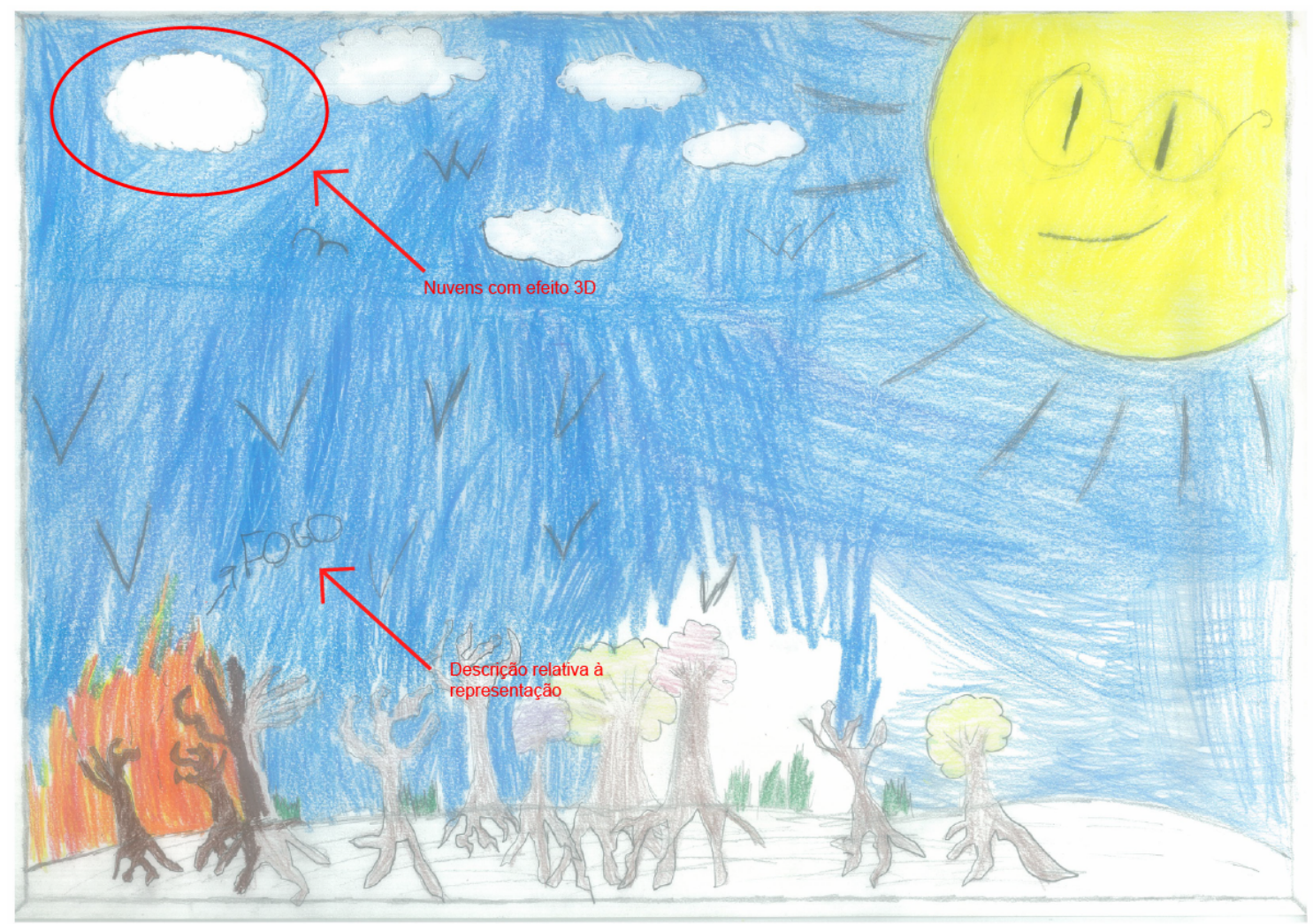

Em outra equipe, os alunos indagaram às pesquisadoras sobre a dificuldade de representar o conteúdo apresentado. Foram estimulados a fazerem da maneira como conseguissem, afirmando que não havia um desenho melhor ou pior e que não havia um só jeito de desenhar. Esses mesmos alunos questionaram sobre a necessidade de pintar e como iriam representar as cinzas, como mostra a figura 6 , a seguir. 
Figura 6: RGS produzida pelos alunos do $5^{\circ}$ ano. Fonte: As autoras, 2021.

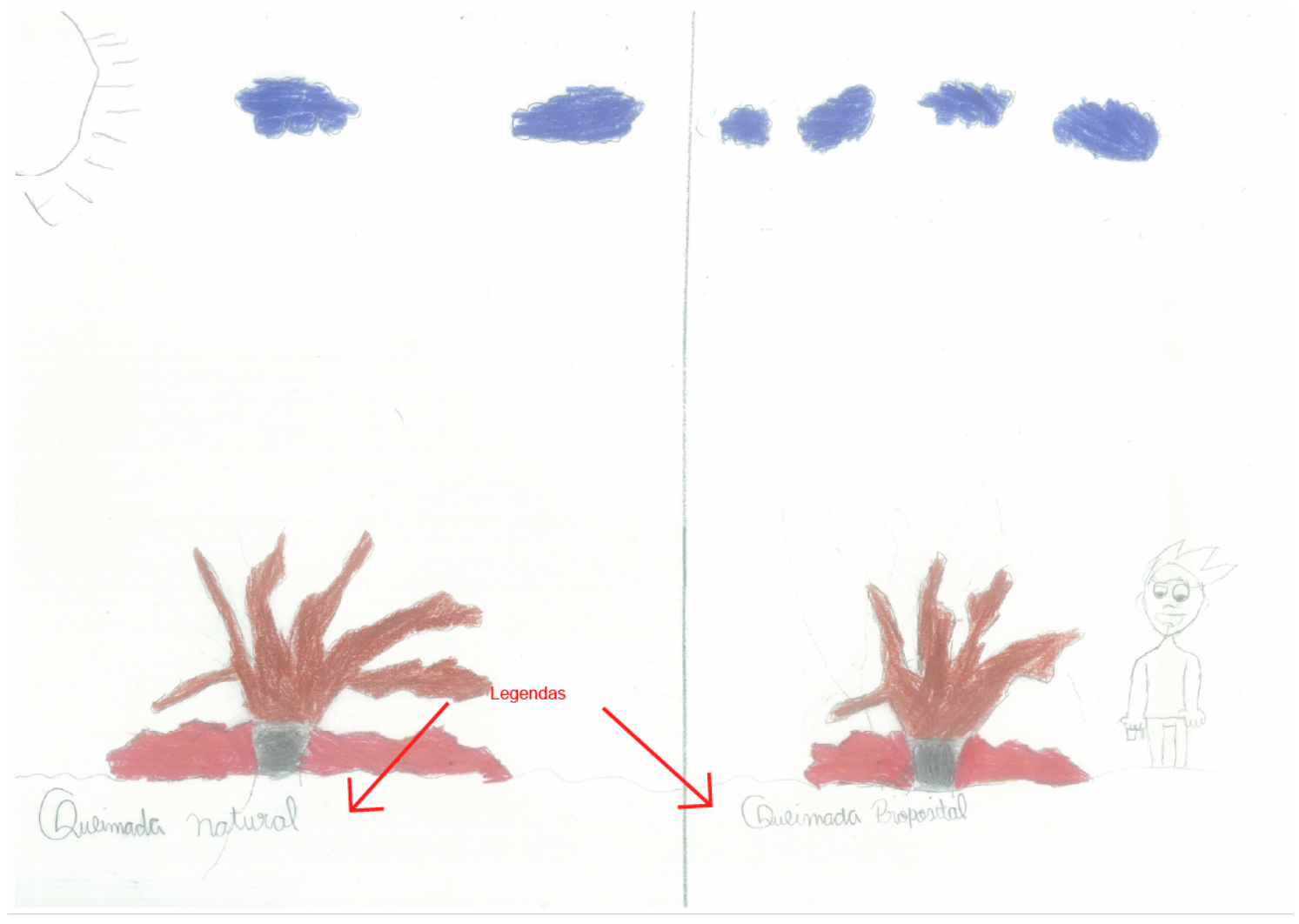

Durante a dinâmica percebeu-se que o tamanho da mesa estava dificultando a colaboração em determinados grupos. As mesas individuais haviam sido agrupadas, por isso optou-se por reorganizar as mesmas, deixando somente uma mesa e colocando quantas cadeiras fossem necessárias ao redor. Esta mudança favoreceu o processo colaborativo.

$\mathrm{Na}$ continuidade da dinâmica foram sendo observados diversos aspectos relevantes a construção da RGS, tais como preocupação estética com a construção de fontes mais elaboradas e a preocupação da correlação das cores com os elementos que estavam representando - vermelho, laranja e amarelo por serem "as cores do fogo", como pode ser observado na Figura 5. As crianças também demonstraram grande preocupação com a indicação de elementos que pudessem complementar a explicação do desenho, tais como textos explicativos na Figura 6 e legendas na Figura 7. 
W. C. S. Pacheco, P. Zimermann, \& S. Padovani | Por que usar RGS -

Figura 7: RGS produzida pelos alunos do $5^{\circ}$ ano. Fonte: As autoras, 2021.

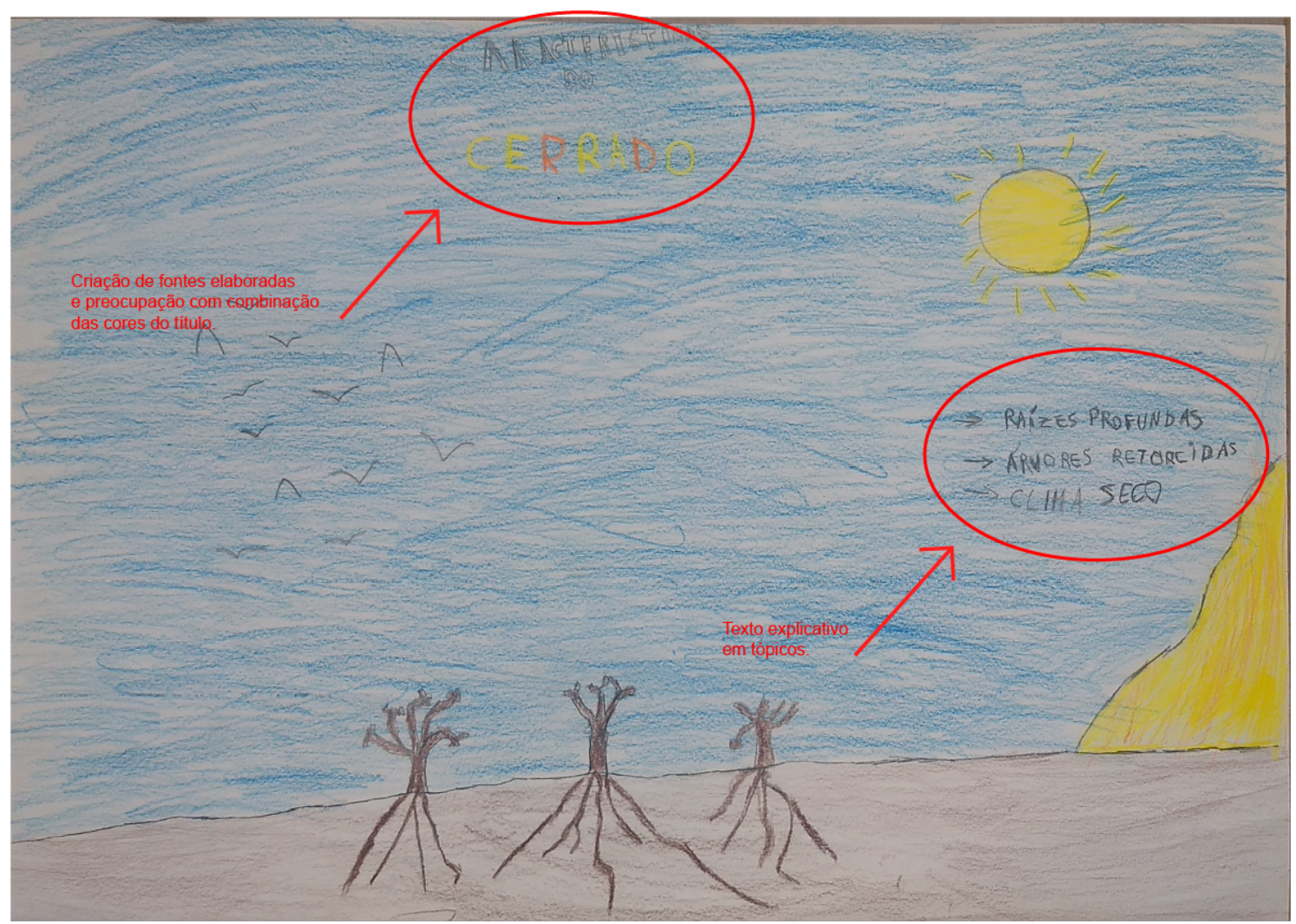

A seleção dos conteúdos e a integração das informações com os elementos representados foi identificada em todas as equipes, por meio de ações colaborativas. No início algumas crianças disseram ser muito difícil trabalhar todas ao mesmo tempo no papel, contudo ao perceberem que o tempo estipulado estava acabando, conseguiram trabalhar colaborativamente. No caso da figura abaixo (FIGURA 08), um dos alunos fez o desenho referência e os demais foram pintando. 
Figura 8: Avaliação da RGS produzida pelos alunos do $4^{\circ}$ ano. Fonte: As autoras, 2021.

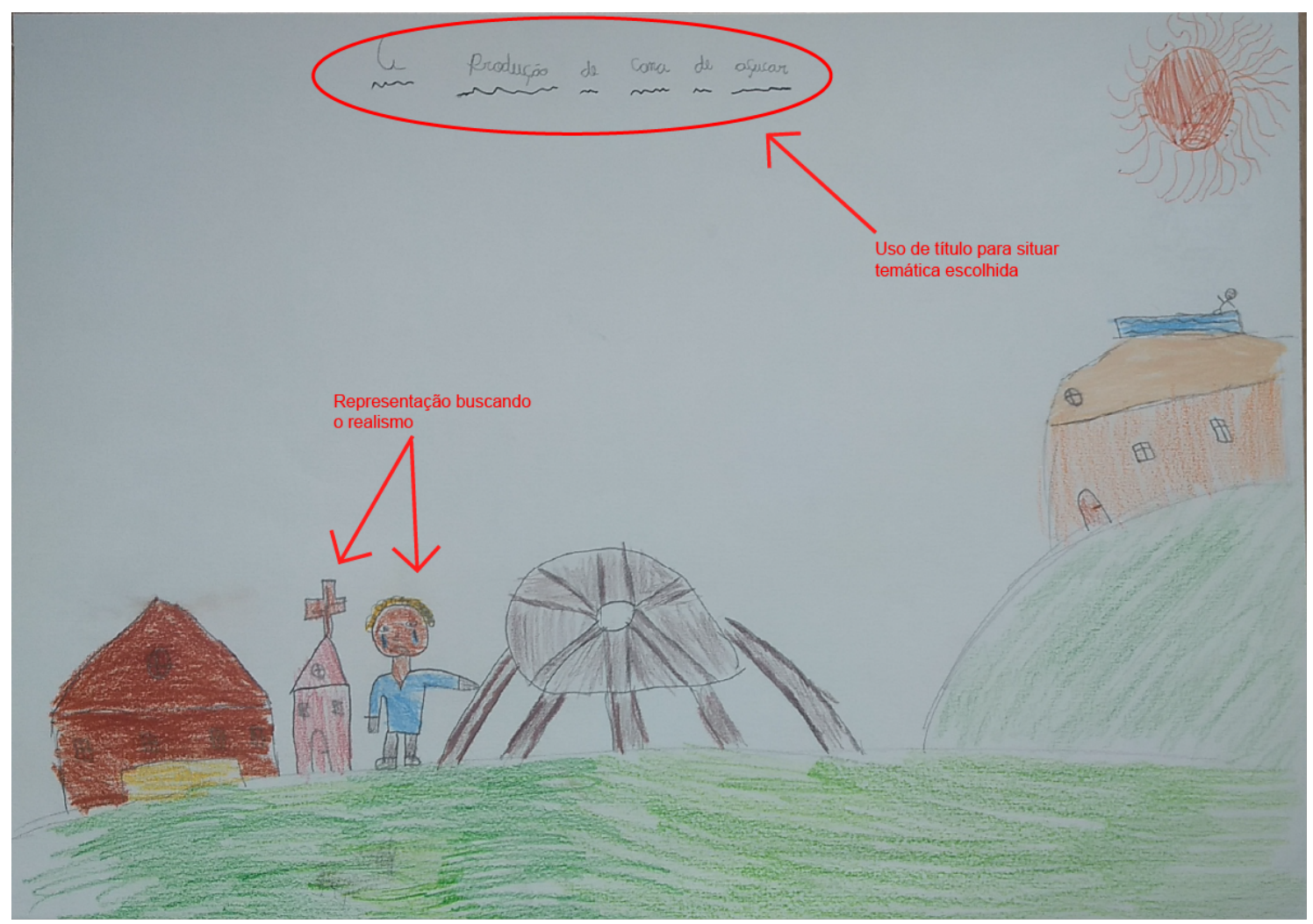

Esses exemplos ilustram algumas das RGSs produzidas pelos alunos. Após a produção, as equipes trocaram as RGSs para iniciar para a etapa de avaliação. Esta análise foi feita em uma folha de overlay - papel vegetal - fixada sobre a criação da equipe e puderam comparar e discutir sobre a produção do outro grupo de colegas, podendo contribuir com críticas, sugestões ou dúvidas.

$\mathrm{Na}$ Figura 9, a seguir, é possível verificar a avaliação da representação de uma equipe de $4^{\circ}$ Ano sobre a produção de cana de açúcar. Os "avaliadores" descreveram desde elementos estéticos - tais como qualidade da letra e da pintura - até questões de conteúdo: como a piscina desenhada sobre a casa grande "não fazer sentido". 
W. C. S. Pacheco, P. Zimermann, \& S. Padovani | Por que usar RGS -

Figura 9: Avaliação da RGS produzida pelos alunos do $4^{\circ}$ ano. Fonte: As autoras, 2021.

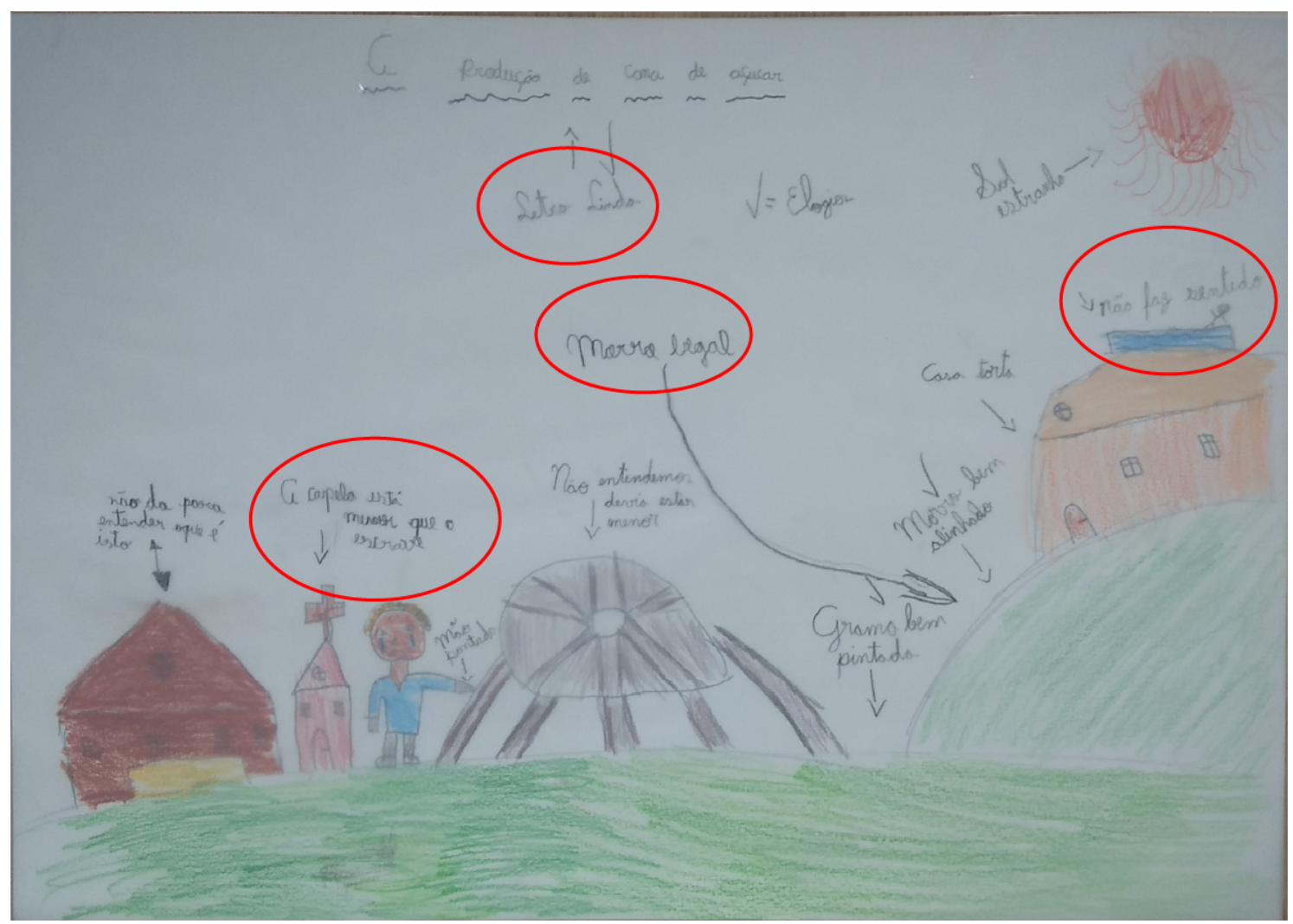

Em outro exemplo de avaliação, os alunos atribuíram nota ao desenho produzido e foram bem criteriosos, fazendo correlações com o conteúdo teórico estudado. Alguns questionamentos levantados foram sobre a falta de clareza de como se iniciou a queimada, sobre a cor da grama branca (se era uma nova espécie), falta de pintura e sobre o bioma não estar representado de forma clara, como mostra a Figura 10. 
Figura 10: Avaliação da RGS produzida pelos alunos do $4^{\circ}$ ano. Fonte: As autoras, 2021.

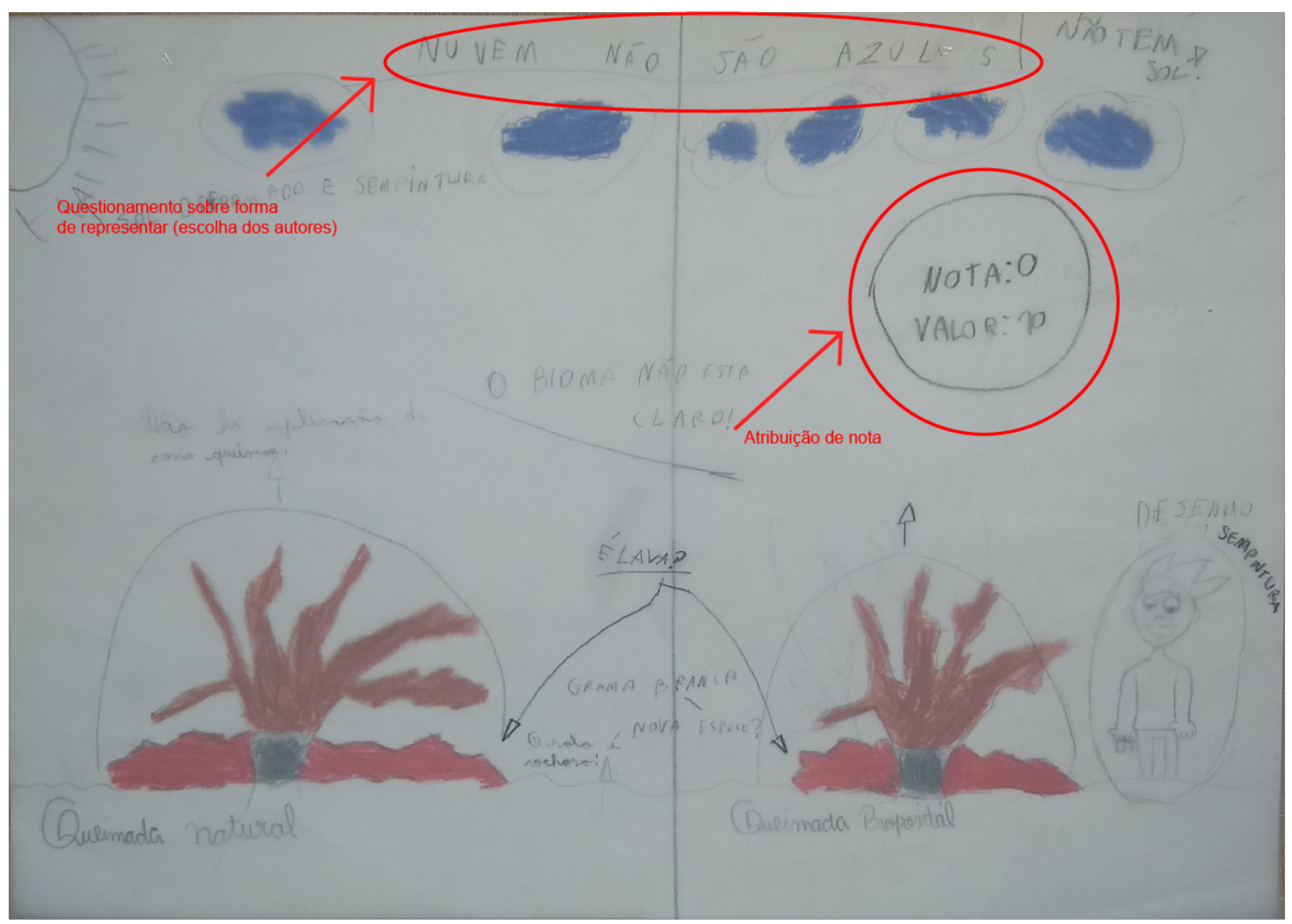

Além dos comentários descritos no overlay, também surgiram comentários verbais que esboçaram a criticidade e o empenho com a dinâmica:

- "-Deveriam ter feitos os negros trabalhando, não só bonecos palitos."

- “-Muito infantil" (sobre o sol desenhado com rostos).

- "- Primeira coisa é melhorar essa letra, né?" (sobre título e legendas de uma das equipes).

- “-Dependendo de quem fez, vou dar uma nota melhor." (buscando identificar os autores)

Sobre este último ponto, foi explicado que o objetivo era a representação e não saber quem fez, para não influenciar. As equipes também ficaram muito interessadas em saber sobre a avaliação dos colegas e quiseram explicar o que a equipe avaliadora não entendeu, resultando em novas discussões sobre o conteúdo e favorecendo o aprendizado.

\section{Discussão}

Padovani et al (2012), indicam objetivos que devem ser analisados para entender se uma RGS foi produzida adequadamente. No contexto desta pesquisa, percebeu-se que as crianças foram capazes de atingir esses objetivos, na maioria dos casos, parcialmente ou completamente. 
Os objetivos aqui analisados foram sob a ótica do Design em relação ao que o BNCC propõe como prioritário nesta nova educação. Os professores nesta fase inicial da pesquisa indicaram conteúdos e disciplinas possíveis de se aplicar uma dinâmica de RGS e auxiliaram na condução da mesma, porém a avaliação foi feita somente pelas pesquisadoras. Os professores farão parte da avaliação no próximo ciclo de coleta de dados, visto que esta pesquisa ainda está em andamento.

Houve a sumarização das partes importantes da aula, quando os alunos conseguiram elencar os tópicos que seriam relevantes para eles na construção da representação, assim como conseguiram esclarecer dúvidas e compartilhar diferentes pontos de vista.

No compartilhamento dos diferentes pontos de vista, foi interessante perceber como a habilidade de argumentação foi trabalhada exaustivamente, havendo negociação e até tentativas de "suborno" para que a ideia fosse acatada pelos demais colegas. O aprimoramento da capacidade descritiva e a exploração de relações dentro do conteúdo são ações que deverão ser aprofundadas com as crianças, pois muitas delas não conseguiram atingir estes objetivos.

A prática da capacidade de julgamento analítico foi parcialmente atingida, pois percebeu-se que os tópicos a serem analisados deveriam ser propostos de modo mais claro aos alunos. Porém, descobriu-se que os alunos têm uma boa capacidade de alternância entre os modos verbal e visual. As habilidades de interpretação e representação gráfica também deverão ser melhor exploradas com os alunos, pois os mesmos não estão acostumados a produzir colaborativamente e com tal liberdade que a RGS propõe.

Quanto a proposição da RGS, para as crianças denominada de desenho, foram encontrados os seguintes pontos:

- o tamanho da mesa pode influenciar o desenvolvimento coletivo;

- ao não ter referências escritas ou físicas sobre o tema, os alunos dispensaram muito tempo em discussão, ficando com pouco tempo para a execução do desenho;

- há uma preocupação estética na forma de representação, seja ela textual ou desenhada. A combinação das cores, proporção dos desenhos e o estilo de representação;

- as crianças são influenciadas sobre como farão a avaliação em função da amizade que mantém com os autores, porém os alunos não têm vergonha de se identificar na crítica que estão anotando;

- ao solicitar a produção de um "desenho", algumas equipes não se preocuparam em fornecer títulos ou legendas (texto curto de apoio), no intuito de complementar, porém durante as avaliações, os alunos queriam "explicar" suas criações.

Inicialmente, produzir um desenho sem regras claras (formato, cores, quantidade de texto) pode ser desafiador, visto que estão acostumados a representar algo proposto. Também foi possível verificar que o processo colaborativo da construção da representação foi relevante e instigante aos alunos, os quais afirmaram, ao final da dinâmica, terem gostado muito. 
A sondagem ocorrida de modo presencial, antes da pandemia do Covid-19, indicou a possibilidade de aplicabilidade das RGSs com este público. Considerando-se os ajustes necessários sobre a proposta de dinâmica de RGS apresentada, conclui-se inicialmente que as crianças são capazes de produzir colaborativamente uma síntese visual, assim como definir atores de um processo coletivo e colaborativo, tornando a aprendizagem real e significativa.

\section{Conclusão e estudos futuros}

O objetivo deste estudo foi verificar como crianças do ensino fundamental 1 - $4^{\circ}$ e $5^{\circ}$ anos trabalham visualmente com a informação e conhecimento adquirido por meio de aulas e materiais didáticos. O artefato utilizado para a avaliação foi a representação gráfica de síntese - RGS.

Após o entendimento teórico sobre o pensamento visual nesta faixa etária e das possibilidades de aplicação com o grupo, foram feitas entrevistas de sondagem com professoras da escola participante e posteriormente estruturada uma dinâmica para os alunos.

A entrevista realizada com professores auxiliou a definição do público-alvo e da estruturação da dinâmica com as crianças. Contribuindo também para clarificar as diferentes técnicas de desenho utilizadas e como seu uso ainda é restrito a momentos de maior descontração, mesmo sendo atividades que geram um maior engajamento dos alunos por serem mais "atrativas". Também compreendeu-se que o desenho não é entendido como parte do processo de assimilação do conteúdo aprendido, ou seja, um texto "bem escrito" é mais importante do que uma representação visual bem-organizada.

Nessa primeira dinâmica, foi necessário que ajustes "repentinos" acontecessem, visto que o padrão estruturado era baseado em estudos realizados com adultos que cursam disciplinas da área do design (graduação e pós), porém, as pesquisadoras envolvidas entenderam que o resultado alcançado é interessante e viável nesta faixa etária e contribuirá com o desenvolvimento de novas dinâmicas em contexto escolar.

Já durante a aplicação da RGS com as crianças percebeu-se um grande entusiasmo em participar da atividade e os alunos demonstraram estar familiarizados com atividades coletivas, porém com dificuldades em ser colaborativa. Eles conseguem trabalhar juntos, porém não desenvolvendo a mesma coisa. Mesmo havendo a dificuldade da colaboração, foi possível observar que houve a discussão sobre o que e como seria executada a tarefa - fato bastante importante no processo de construção da RGS - e a participação de todos os integrantes no desenvolvimento do desenho, cada um no seu tempo e na sua maneira, mas houve a colaboração.

Considerando os elementos de uma RGS em relação ao resultado que os alunos apresentaram, verifica-se que ocorreu a sintetização da informação (diversos tópicos apresentados $X$ escolha de um ou alguns para representação), houve a ação colaborativa (distribuição de tarefas e execução) e ocorreu a avaliação (não somente críticas pessoais, mas principalmente críticas em relação ao conteúdo). 
Em relação aos elementos de design (tipografia, cores, hierarquia, representação, entre outros) percebe-se a preocupação por parte dos alunos, que buscam sempre a "melhor" maneira de transpor para o papel seus desejos. Há também uma preocupação excessiva dos alunos sobre a qualidade do desenho e da forma de representação. Muitos alegam não saber desenhar. O que pode ser trabalhado durante a proposição da RGS.

Serão necessários ajustes e melhorias no modelo da dinâmica para que o efetivo sucesso seja alcançado. Os ajustes visam refinar um modelo que foi estruturado para reprodução de alunos jovens|adultos e com formação no campo do Design e que apresentam facilidade e prática com o pensamento visual. Abaixo seguem os pontos identificados até o momento que deverão ser revistos para pesquisa futuras:

- Tempo destinado à atividade - tempo total e sub etapas.

- Forma de instruir a dinâmica - clareza, porém com detalhes suficientes que auxiliem o aluno na condução do trabalho.

- Estímulo ao trabalho colaborativo - restringir tamanho da mesa seria eficiente?

- Fornecer referências escritas e físicas podem ser necessários.

- Verificar como as RGSs estão sendo percebidas pelos integrantes (cumprir com o requisito - percepção).

- Processo avaliativo entre grupos - alunos precisam ser imparciais?

- Houve consistência de conhecimento, correlacionando com os demais conteúdos da disciplina?

- Delimitar os elementos hierárquicos? Necessidade ou não de títulos, legendas, palavras-chave.

\section{Agradecimento}

O presente trabalho foi realizado com apoio da Coordenação de Aperfeiçoamento de Pessoal de Nível Superior Brasil (CAPES) - Código de Financiamento 001.

\section{Referências}

Ampieri, R. H.; Collado, C. F.; Lucio, M. Del P. B. (2013) Metodologia de Pesquisa. 5a edição ed. Porto Alegre: Penso

Arnheim, R. (1969). Visual thinking. Berkeley: University of California Press.

Baker, F. W. (2012) Chapter 3: Visual literacy. In: Media Literacy in the K-12 Classroom. [s.I.] ISTE - International Society for Technology in Education. v. 3777p. 41-71.

Barbosa, G. S.; Magina, S. M. P. (2012) Atividades Lúdicas Como Um Caminho Didático Apropriado Para Introduzir Conceitos Associados Ao Número Primo. Educação Matemática Pesquisa. Revista do Programa de Estudos Pós-Graduados em Educação Matemática. ISSN 1983-3156, v. 14, n. 1, p. 127-148.

Brasil. Ministério da Educação. Base Nacional Comum Curricular. Proposta preliminar. Segunda versão revista. Brasília: MEC, (2016). Disponível em: <http://basenacionalcomum.mec. gov.br/documentos/bncc-2versao.revista.pdf>. Acesso em: 01 dez. 2017. 
Bueno, J.; Padovani, S. (2015) Estudo do processo de aprendizagem colaborativa através das representações gráficas de síntese (RGSs). 7th Information Design International Conference (CIDI), v. 2, n. 2010, p. 374-385.

Bussarello, R. I; Ulbrich, V. R. (2013) Aprendendo por quadrinhos hipermídia: o discurso de alunos surdos sobre essa proposta de aprendizagem. In: Mídia e educação: novos olhares para a aprendizagem. P. 148-167.

Calomeno, C. (2017) Simuladores Educacionais: Definições, Tensões E Apropriações Como Objetos De Aprendizagem. Educação Gráfica, v. 21, p. 257-269.

Carter, N. (2019) Sketchnoting In The Classroom: A pratical guide to deepen student learning. 1a ed. Portland e Arlington: ISTE - International Society for Technology in Education.

Comissão Internacional sobre Educação para o Século XXI. Educação: um tesouro a descobrir, relatório para a UNESCO da Comissão Internacional sobre Educação para o Século XXI (destaques) (2010). Brasília: UNESCO. Disponível em <https://unesdoc.unesco.org/ark:/48223/pf0000109590_por>. Acesso em 14 mai. 2020.

Fish, J.; Scrivener, S. (1990) Amplifying the Mind's Eye: Sketching and Visual Cognition. Leonardo, v. 23, n. 1, p. 117-126.

Lopatovska, I.; Hatoum, S.; Waterstraut, S.; Novak, L.; Sheer, S. (2016) Not just a pretty picture: visual literacy education through art for young children. Journal of Documentation, v. 72, n. 6 , p. 1197-1227.

Machado, G. B. et al. (2015) Representação Do Conhecimento Através De Pensamento Visual : Uma Experiência Em Sala De Aula. Competência, v. 8, n. 2, p. 91-106.

Moreira, M. A. (2012). O que é afinal aprendizagem significativa? Qurriculum, La Laguna, Espanha.

Norman, D. N. (1991) Cognitive artifacts. Cambrige: Cambridge University Press.

Padovani, S. (2012) Representações gráficas de síntese: artefatos cognitivos no ensino de aspectos teóricos em design de interface. Educação Gráfica, v. 16, n. 02, p. 123-142.

Padovani, S. et al. (2016) Representações Gráficas de Síntese (RGS) como artefatos cognitivos para aprendizagem colaborativa Graphic Representations for Synthesis (GRS) as cognitive. Estudos em Design, v. 24, n. 1, p. 45-70.

Padovani, S.; Bueno, J.; Oliveira, J. F. de.(2020) Representações Gráficas de Síntese (RGS): em busca de uma elucidação do conceito. InfoDesign, v. 17, n. 1, p. 131-151.

Roam, D. (2008) The Back of the Napkin: Solving Problems and Selling Ideas with Pitcures. Ed Portfolio.

Rosso, A. T. De P.; Schlögl, L. (2013) Histórias Em Quadrinhos Enquanto Meio De Comunicação Eficaz. Razón y Palabra: Revista Electrónica en Iberoamérica Especializada en Comunicación, n. 83, p. 27.

Santos, A. dos. (2018) Seleção do Método de Pesquisa. Curitiba: Insignt Editora.

Willis, C.; Miertschin, S. (2006) Mind maps as active learning tools. Journal of Computing Sciences in Colleges, v. 21, n. 4, p. 266-272, 2006. 


\section{Sobre as autoras}

Waleska C. Sieczkowski Pacheco, Msc., UFPR | Unicuritiba, Brasil <pacheco.waleska@gmail.com>

Priscila Zimermann, Msc., UFPR, Brasil <pri.zimermann@gmail.com>

Stephania Padovani, Dra., UFPR, Brasil <s_padovani2@yahoo.co.uk> 